\title{
Do slot machines play mind games with gamblers?
}

$\mathrm{T}$ he room is abuzz with beeps, bells and flashing lights. Welldressed men and women wander about, pushing buttons and pulling levers, watching cherries and sevens spin on liquid crystal displays. But these men and women aren't here for fun. They're here for business, and their business is gambling.

From April 29 to May 1, 2008, the Palais des Congrès de Montréal in Montréal, Quebec, hosted the 12th annual Canadian Gaming Summit. In a massive showroom, slot machine makers from across the country presented their wares: tall, noisy boxes decorated with images of pigs and pirates and martini glasses.

Though diverse in appearance, all slot machines, according to some mental health experts, have something in common: they are psychologically deceptive and make gambling addicts of people who aren't predisposed to addictions.

"We've been treating these people like they're messed up, but it's the machines that are messing them up," says Roger Horbay, a former addiction therapist who now runs Game Planit
Interactive Corp., a company that advocates for consumer protection in the gambling industry.

Advocates for the gambling industry disagree, claiming electronic gaming machines are benign - designed to entertain, not manipulate.

Problem gambling prevalence studies show that gambling addicts are much more likely to play electronic gaming machines (slot machines, poker machines, video lottery terminals) than table games like blackjack. A 2003 survey indicated that almost half of video lottery terminal players in Nova Scotia were at risk for problem gambling. The Alberta Alcohol and Drug Abuse Commission reported in 2003 that $71 \%$ of its clients with gambling addictions had no problems before playing video lottery terminals. One study found that some $60 \%$ of gaming machine revenue in Canada comes from problem gamblers. By contrast, problem gamblers accounted for less than a quarter of lottery and bingo revenues (Analyses of Social Issues and Public Policy 2004;4[1]:33-45).
Canadians hooked on gaming machines suffer little inconvenience in finding their next fix. Ontario has about 22000 gaming machines, all slots. Quebec has a mix of slots and video lottery terminals, almost 19000 in total. In Newfoundland, where bars have no competition from casinos or racetracks, there are about 2500 video lottery terminals: per capita, 3 times more than Ontario.

All those machines make for big profits. Of the $\$ 4.7$ billion reaped by Ontario's gambling industry in fiscal year 2006/07, \$3 billion came from slot machines. The percentage of fiscal year 2006/07 gambling revenues from electronic gaming machines in Manitoba, Saskatchewan and Alberta was 79\% (of $\$ 615$ million), 83\% (of \$535 million) and $87 \%$ (of $\$ 2.2$ billion), respectively.

Before gaming machines exploded in popularity in the $1990 \mathrm{~s}$, most of the gambling addicts Horbay saw had other psychosocial problems. This indicated they were likely predisposed to addiction. But as the number of problem machine gamblers increased, he noticed many didn't exhibit other addictive be-

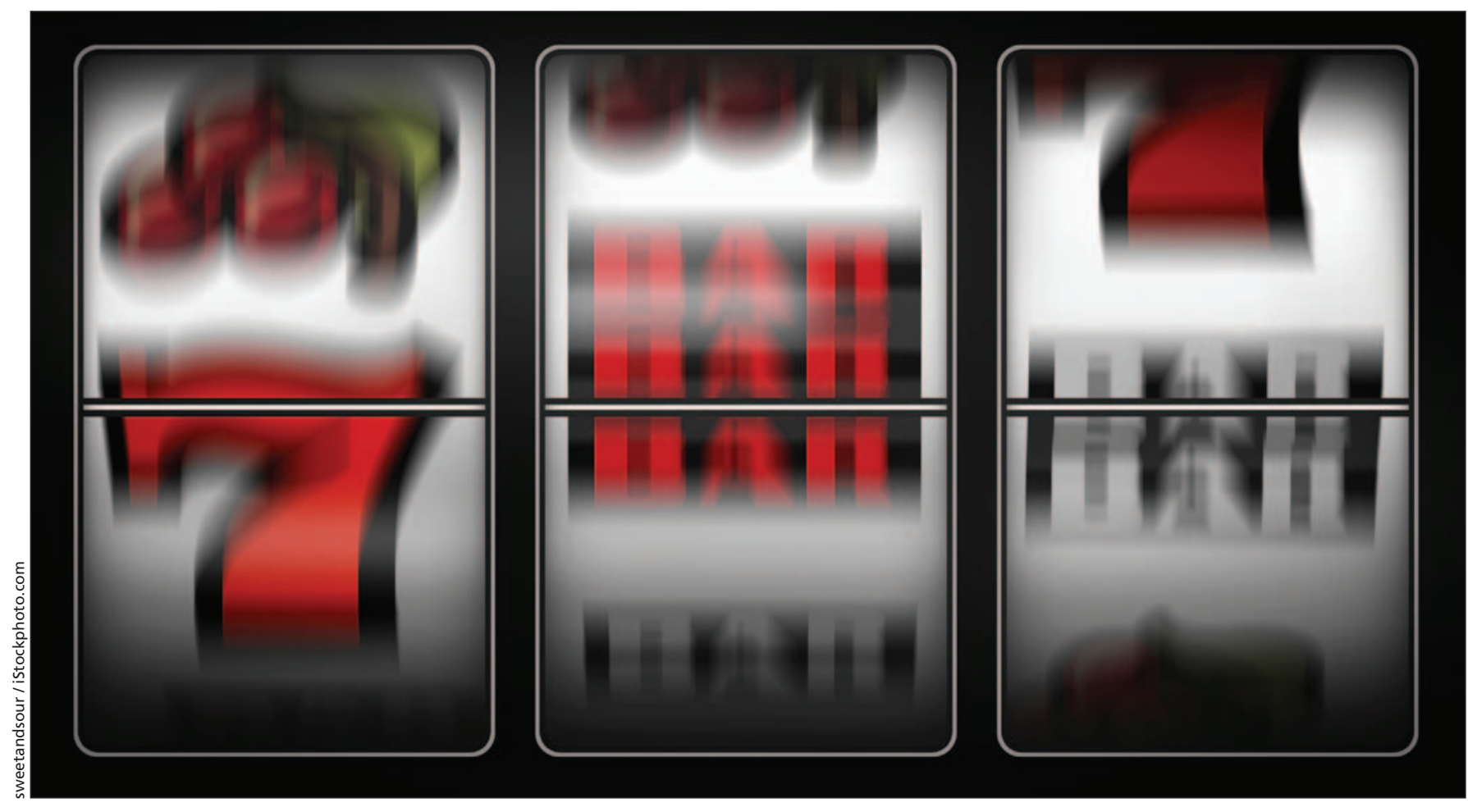

It may seem as if uncertainties shroud slot machines and other electronic gaming machines, but several things are clear: they're a cash cow for governments and use technologies that are considered deceptive. 
haviours. They were what Horbay refers to as "normals."

"In other games, like poker, most people have misconceptions about their skill levels. They are easier to treat. But machine gamblers really are conditioned by the machine. You get the impression you can beat the machine."

As a result, says Horbay, many people have been led to believe they are suffering from cognitive distortion when, in reality, they are reaching proper conclusions based on misleading information. Research out of the University of Waterloo shows that the features of a typical slot machine suggest that players should win about 2 to 5 times the amount they wager, which, if true, would mean casinos lose money on slots (Journal of Gambling Issues 2007;20:215-33). Logic dictates that casinos wouldn't line their floors with row upon row of slot machines if they weren't cash cows. But critics of gambling practices claim the devices condition users to abandon logic.

Robert Simpson, chief executive officer of the Ontario Problem Gambling Research Centre, claims slot machines are designed to create an illusion of favourable odds that gets people playing — and keeps them playing. "All these design characteristics in EGMs [electronic gaming machines] give people the wrong impression of how the machines work, such that they actually believe that over time, the more they play, the more likely they are to win."

Horbay and Simpson both cite a slot machine feature called virtual reel mapping as being particularly deceptive. Old mechanical slot machines had a set number of reels containing a set number of symbols, each equally likely to appear on the payline after each spin. In the 1980s, however, slots makers incorporated electronics into their products and programmed them to weigh particular symbols. Thus the odds of losing symbols appearing on the payline became disproportionate to their actual frequency on the physical reel. The 1984 patent granted on this technology (United States Patent No. 4448 419) states: "It is important to make a machine that is perceived to present greater chances of payoff than it actually has within the legal limitations that

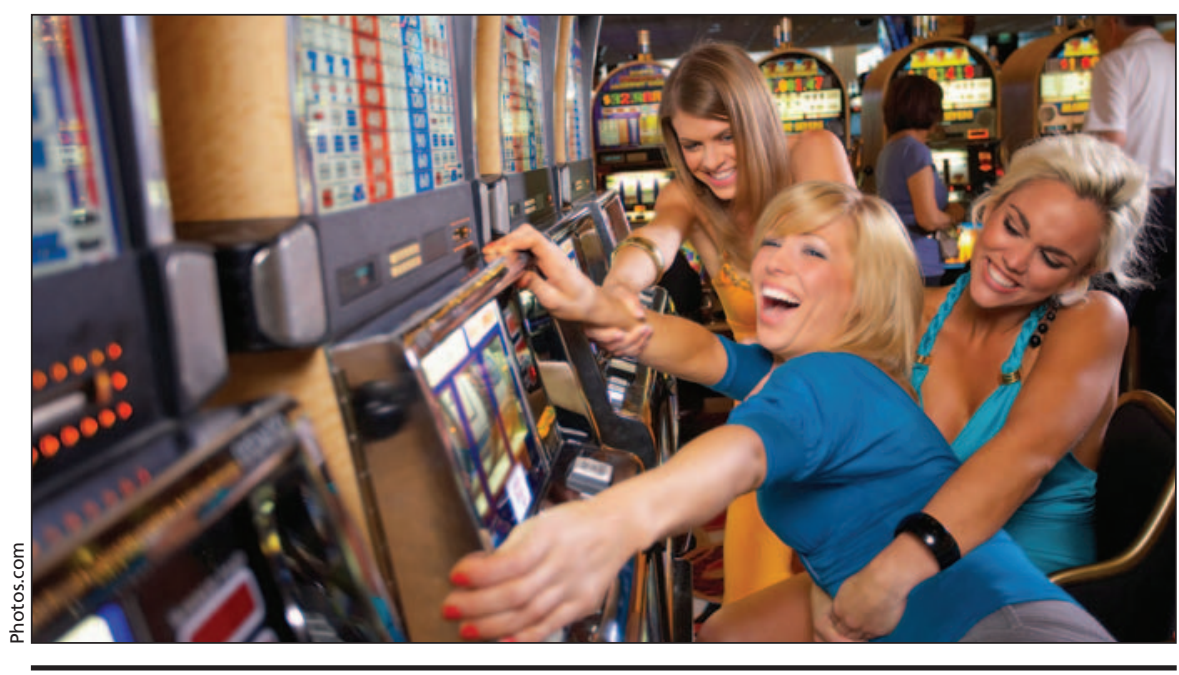

Slot machines don't manipulate, they entertain, the gambling industry says.

games of chance must operate."

The Waterloo research paper indicates virtual reel mapping also increases the probability that winning combinations will appear just above or below the payline, which, according to addiction experts, makes gamblers believe they are always on the verge of winning. Gamblers are also largely unaware that the reels on slot machines are often unbalanced. On a 3-reel machine, for example, a winning symbol may appear more often on the first 2 reels than on the last. Many modern gaming machines use electronic animation instead of reels, but a disconnect remains between how the game is displayed and how it actually operates. Other features considered deceptive by critics include differing symbol sizes (winning symbols are larger), stop buttons (give the illusion of control though the outcome is determined on initial wager) and frequent small wins (accompanied by flashing lights and bells).

Bill Rutsey, chief executive officer of the Canadian Gaming Association, an organization that calls itself "the voice of Canada's gaming entertainment industry," says most gamblers know gaming machines have random outcomes and play them for excitement. Virtual reel mapping and unbalanced reels are not deceptive features, he says.

"The whole issue there is did you win or didn't you win. If you didn't win, you didn't win. I think it's pretty clear when you're playing the game whether or not you've won, or when you do win and when you don't win ... whether the reel is balanced or unbalanced, you end up with the same result. Either you have a winning combination or you have a losing combination."

The reason problem gamblers prefer gaming machines is also easy to explain, says Rutsey. Research shows that about $1 \%$ of the population are problem gamblers. Since about $75 \%$ of casino patrons list slots as their favourite game, it only makes sense, he says, that many problem gamblers fall within that majority. To claim the machines make addicts is untrue, he adds. "It's kind of like saying beer causes alcoholism because most alcoholics drink beer."

Horbay, however, considers machine gaming the most addictive, and yet least regulated, form of gambling. Casinos would never get away with using loaded dice or with stacking a deck of cards, he says, which are akin to the deceptive features of gaming machines. He proposes that the government phase out virtual reel mapping (already illegal in Australia and New Zealand) and unbalanced reels. Gamblers would also suffer fewer problems, he says, if electronic gaming machines displayed how much they stand to lose on each bet.

"The treatment field has been doing these players a disservice," says Horbay. "Let's stop labeling and pathologizing them. These are normal people. Let's look at the source of the harm." — Roger Collier, CMAJ

DOI: $10.1503 / \mathrm{cmaj} .080870$ 